\title{
A Study on Effects of Magnesium Sulphate Infusion in Preventing Cardiac Arrhythmia During Off Pump Beating Heart Coronary Artery Bypass Grafting (CABG) Surgery
}

\author{
Samar Chandra Saha, ${ }^{1}$ Md. Ataur Rahman, ${ }^{2}$ Shafeya Khanam, ${ }^{3}$ Saria Sharmin ${ }^{4}$
}

\begin{abstract}
Objective: The objective of the present study was to see the effect of magnesium in preventing cardiac arrhythmias in patients undergoing coronary artery bypass grafting (CABG) surgery.

Methods: This study was carried out in the Department of Anesthesia, Analgesia and Intensive Care Medicine (Cardiac Anesthesia Wing) of Bangabandhu Sheikh Mujib Medical University (BSMMU), Dhaka who underwent CABG surgery under general anaesthesia. A total of 60 patients scheduled for CABG were consecutively selected and were randomly divided into study group and control group. Patients aged 35-70 years irrespective of sex, ASA grade I \& II, NYHA functional class I \& II and ejection fraction 35-65\% were included in the study. The study group was treated by vecuronium, fentanyl and magnesium sulphate infusion, while the control group was treated by vecuronium and fentanyl infusion. The demographic variables, preoperative clinical characteristics, peroperative variables and haemodynamic findings were observed at different time intervals.
\end{abstract}

Results: The mean ages of the study and control groups were $51.0 \pm 6.9$ years and $53.8 \pm 6.2$ years respectively. Males demonstrated their predominance in both magnesium (83.3\%) and control (76.7\%) groups. The distribution of preoperative confounding factors like diabetes, previous MI, hypertension and ejection fraction were not statistically different between the study groups. Two-thirds (67.7\%) of the patients in magnesium group and $53.3 \%$ in the control group required 3 grafts. Number of 4 grafts in magnesium and control groups was $20 \%$ and $30 \%$ respectively and that of 2 grafts was $13.3 \%$ and $16.7 \%$ respectively. In the study group, out of 30 patients, 3(10\%) developed arrhythmia, while in the control group out of 30 patients, $5(16.7 \%)$ developed arrhythmia $(p=0.353)$. The haemodynamic parameters in patients receiving magnesium were more stable during the whole period of observation.

Conclusion: The findings of the study suggest that magnesium could reduce the development of arrhythmia to an acceptable level in patients undergoing beating heart CABG surgery. However, further study with large sample is recommended to achieve a conclusive remark.

Key words: Magnesium sulphate, off-pump, beating heart, coronary artery bypass grafting, cardiac arrythmia etc.

\section{INTRODUCTION:}

Among cardiac surgical diseases coronary artery disease is one of the leading causes of death in both developed and developing countries. Despite significant progress in nonsurgical management of coronary artery disease like stent technology and anticoagulant therapy (e.g. Clopidogrel, which has improved the long-term patency after angioplasty), the usefulness of coronary artery bypass graft surgery has not reduced; rather it is gaining popularity day by day. Cardiac dysrhythmia is commonly seen after CABG surgery. The incidence of postoperative supraventricular arrhythmia has been reported to be $11-54 \%$ and the incidence of

\section{Authors' information: \\ ${ }^{1}$ Dr. Samar Chandra Saha, MBBS (DMC), DA (DMC), FCPS (Anaesthesiology), Registrar, Department of Anaesthesiology, Holy Family Red Crescent Medical College Hospital Dhaka, Bangladesh}

${ }^{2}$ Dr. Md. Ataur Rahman, MBBS, DA (DU), MCPS (Anaesthesiology), Assistant Professor, Department of Anaesthesiology, Rangpur Medical College, Rangpur.

${ }^{3}$ Dr. Shafeya Khanam, MBBS, BCS (Health), FCPS, MS, Associate Professor (Obstetrics \& Gynaecology), Faridpur Medical College, Faridpur.

${ }^{4}$ Dr. Saria Sharmin, Jounior Consultant, Institute of Child \& Maternal Health, Matuail, Dhaka.

Correspondence: Dr. Samar Chandra Saha, Cell Phone: +88 01715867678, E-mail: samarsaha50@gmail.com 
ventricular arrhythmia to be $2-13 \%$ in open heart bypass surgery. ${ }^{1}$ Knowledge of aetiology \& progression of arrhythmia may allow us to reduce the use of pharmacological and electrical procedures aimed at assuring normal sinus rhythm. Most antiarrhythmic medications currently used (beta-blockers and amiodarone) have some side effects. The decrease in the concentrations of ions such as potassium and magnesium is an important factor in most of the cases of arrhythmia that do not have organic causes. ${ }^{1}$ Identifying and detecting these ionic imbalances may protect the heart from side-effects of anti-arrhythmic drugs. Cardiac dysrhythmia potentially leads to complications, including thromboembolic events, hemodynamic disorders, prolonged hospital stay and increased costs. ${ }^{2}$ It is not only a rhythm disturbance, but also quite a serious morbidity factor because of its complications and therefore, prophylaxis is very important.

Magnesium sulphate prevent the development of arrhythmia both intraoperatively \& postoperatively. ${ }^{3}$ Magnesium is a cation, the serum level which is tightly regulated in a narrow range of approximately $0.7-1.0 \mathrm{mmol} / \mathrm{L}$, for only $1 \%$ of the total body content of magnesium is extra cellular. ${ }^{4}$ When serum ionized magnesium level falls below $0.7 \mathrm{mmol} / \mathrm{L}$, it is, although controversial, indicative of arrhythmia. As only $1 \%$ of the total body magnesium is extracellular, the value of measuring the serum levels has been questioned. ${ }^{5}$

The mechanism of action by which magnesium sulphate prevents arrhythmia is unclear. The oretically prolongation of the cardiac action potential by lengthening the refractory period at the atrioventricular mode could be achieved. ${ }^{1}$ Magnesium is a natural calcium blocker. ${ }^{5}$ Alteration of intra and extra cellular magnesium concentration may affect cell function through their effect on calcium handling. ${ }^{4}$ Magnesium is essential for the replication and transcription of DNA, as well as cellular energy metabolism, membrane stabilization, nerve conduction and calcium channel function. ${ }^{5}$ This study was therefore, intended to find the efficacy of magnesium sulphate in preventing arrhythmia in patients undergoing beating heart CABG surgery.

\section{METHODS:}

The present cross-sectional study was carried out in Department of Anesthesia, Analgesia and Intensive Care Medicine (Cardiac Anesthesia Wing) of Bangabandhu Sheikh Mujib Medical University, Dhaka. over a period of 1 year from January 2009 to December 2009. Patients undergoing CABG surgery under general anaesthesia were the study population. Patients with age ranging between 35-70 years irrespective of sex, ASA grade I \& II, NYHA functional class I \& II and ejection fraction $35-65 \%$ were eligible for study. However, patients with severely impaired liver and kidney function, emergency operation and reoperation were excluded. A total of 60 patients were consecutively included in the study and were randomly allocated into the study and control groups. Patients of the study group were treated by vecuronium, fentanyl and magnesium sulphate infusion, while those of the control group were treated by vecuronium and fentanyl infusion.

All patients were examined pre-operatively, and were advised to take tab. Midazolam $7.5 \mathrm{mg}$ at the night before operation. After entering into OT pre-oxygenation was done with face mask for 5-6 minutes with oxygen flow 5-6 L/min. Baseline blood pressure, heart rate, $\mathrm{SPO}_{2}$ all were recorded. Intravenous cannulation was done and an isotonic fluid started. Intraarterial cannulation was done usually at radial artery with 20G cannula and blood pressure was recorded. Induction was done by propofol 1-2.5 mg/kg IV, fentanyl $1-2 \mathrm{mg} / \mathrm{kg}$ \& vecuroneum $0.08-0.1 \mathrm{mg} / \mathrm{kg}$. Intubation was done 3 min after the administration of vecuroneum. Right internal jugular venous cannulation was done for monitoring the central venous pressure and administration of drugs. Temperature probe and urinary catheter were introduced subsequently. After intubation patients were kept on ventilator and intermittent positive pressure ventilation (IPPV) was started. Patients of both groups were then maintained with oxygen $\left(\mathrm{O}_{2}\right) 50 \%$, Nitrous Oxide $\left(\mathrm{N}_{2} \mathrm{O}\right) 50 \%$ and propofol infusion (200 $\mathrm{mg}$ propofol diluted in $100 \mathrm{ml}$ normal saline \& given IV at the rate of 20-25 micro-drop/min). Patients of study group were maintained with magnesium sulphate infusion 
(2.47 gm Magnesium sulphate diluted in $100 \mathrm{ml}$ normal saline and given through microbore at the rate of 20-25 micro- drop/min, i.e., $1.0-1.25$ $\mathrm{mg} / \mathrm{kg} / \mathrm{hr}$ ), Fentanyl infusion $0.4-0.5 \mathrm{mg} / \mathrm{kg} / \mathrm{hr}$, vecuroneum bromide infusion $0.04-0.05 \mathrm{mg} / \mathrm{kg} / \mathrm{hr}$. Patients of Control group were maintained with fentanyl \& vecuroneum bromide infusion (without magnesium sulphate). Arterial blood gas (ABG) and electrolytes were measured every 15 minutes interval. Other causes of perioperative arrhythmia such as hypoxia, hypercarbia, electrolyte imbalance, etc. were corrected. Blood pressure, heart rate, CVP was maintained within acceptable range by adding ionotropes and vasodilator-ionotropes-Dopamine, adrenaline and noradrenaline, vasodilators-GTN. Arrhythmia was managed by several antiarrhythmic drugs such as-Lignocaine, Digoxin \& Amiodarone (Cordarone). At the end of the operation all patients were transferred to Cardiac Intensive Care Unit (ICU) and were kept on ventilator. Patients were extubated in ICU when criteria of extubation fulfilled.

Collected data were entered into the computer program SPSS (Statistical Package for Social Science), version 11.5. Both descriptive and inferential statistics were used in data analysis. The descriptive statistics were frequency, mean and standard deviation from the mean (SD), while the inferential statistics were Chi-square $\left(\chi^{2}\right)$ Test, Fisher's Exact Test and Repeated Measure ANOVA. The level of significance was set at 0.05 and $p<$ 0.05 was considered significant.

\section{RESULTS:}

Age distribution shows that half of the magnesium group was found to lie between 50-60 years followed by $36.7 \%$ below 50 years and $13.3 \% 60$ or $>60$ years. A similar age distribution was also found in the control group $(p=0.636)$. Males demonstrated their predominance in both magnesium (90\%) and control $(93.3 \%)$ groups. The two groups did not differ in terms of sex distribution $(p=0.613)$ (Table I). The use of calcium channel blockers was identical between groups (50\% in each group). Over one-third $(36.7 \%)$ of patients in Magnesium had a history of receiving beta-blockers compared to $16.7 \%$ in Control $(p=0.080$ ) (Table II). None of the risk factors like diabetes, previous MI, hypertension and ejection fraction were found to be significantly different between the study groups $(p=0.432, p$ $=0.542, p=0.584$ and $p=0.143$ respectively) (Table III). Classification of ischemic heart diseases by NYHA functional class demonstrates that class-I disease was $30 \%$ in Magnesium group and $53.3 \%$ in Control, while NYHA class-II was $70 \%$ in the former group and $46.7 \%$ in the latter group. The Chi-square $\left(\chi^{2}\right)$ test revealed that distribution of NYHA functional class between the study groups was statistically different $(p=0.037)$ (Fig.1). Two-thirds $(53.3 \%)$ of patients in the magnesium group and $53.3 \%$ in the control group required 3 grafts. Number of 4 grafts in magnesium and control groups was $20 \%$ and $30 \%$ respectively and that of 2 grafts was $13.3 \%$ and $16.7 \%$ respectively. The groups were not statistically different in terms of number of grafts $(p=0.301)$ (Table IV). Three $(10 \%)$ of 30 patients in magnesium group developed arrhythmia compared to $5(16.7 \%)$ patients in control group. Two-third (66.7\%) of patients of magnesium group developed arrhythmia between 1-1.5 hours and $33.3 \%$ between $1.5-2$ hours of initiation of operation, where as $80 \%$ of control group developed arrhythmia between 1-1.5 hours and $20 \%$ between $1.5-2$ hours. Three patients in the magnesium group and 4 patients in the control group developed atrial fibrillation. All arrhythmiarelated variables were identical in the both groups $(p>0.05)$ (Table V). Table VI \& Fig 2 shows the comparison of changes in systolic blood pressure at different time intervals. The mean systolic blood pressure of magnesium and control groups exhibited a sharp decrease from around $138 \mathrm{mmHg}$ at baseline to about $110 \mathrm{mmHg}$ and $105 \mathrm{mmHg}$ respectively at 2 hours interval. It then again began to increase in the both groups reaching a mean blood pressure of $120.3 \mathrm{mmHg}$ in the former group and 126.5 in the latter group at 4 hours intervals. Table VII \& Fig 3 demonstrates the changes in diastolic blood pressure between groups. The mean diastolic blood pressure of magnesium group was $85.2 \mathrm{mmHg}$ at baseline which gradually fell to 78.3 $\mathrm{mmHg}$ at 2 hours interval. The control group also experienced a similar decrease up to 2 hours. Then 
both the groups assumed a sharp increase reaching 82.2 and $82.9 \mathrm{mmHg}$ at 3 hours interval. At 4 hours interval the DBP was significantly less in the magnesium group than that in the control group $(p=0.007)$. Table VIII depicts that the heart rate of control group increased from $74 \mathrm{bpm}$ at baseline to $90 \mathrm{bpm}$ at 1 hour. Then it declined up to 2.5 hours and again took a U-turn to reach $86 \mathrm{bpm}$ at 4 hours interval. The heart rate of magnesium group experienced a sharp fall and rise from baseline to the end of observations. Table IX shows the comparison of changes in mean CVP at different time intervals. At baseline the mean CVP of magnesium group was $10 \mathrm{~cm}$ and that of control group was $11.9 \mathrm{~cm}$ of water. Then both groups experienced a fall and rise up to 4 hours of observation.

\begin{tabular}{|c|c|c|c|}
\hline \multirow{2}{*}{$\begin{array}{l}\text { Demographic } \\
\text { characteristics }\end{array}$} & \multicolumn{2}{|c|}{ Group } & \multirow[b]{2}{*}{$p$-value } \\
\hline & $\begin{array}{l}\text { Magnesium } \\
\quad(n=30)\end{array}$ & $\begin{array}{l}\text { Control } \\
(n=30)\end{array}$ & \\
\hline \multicolumn{4}{|l|}{ Age (years) } \\
\hline$<50$ & $11(36.7)$ & $8(26.7)$ & \\
\hline $50-60$ & $15(50.0)$ & $16(53.3)$ & 0.636 \\
\hline$\geq 60$ & $4(13.3)$ & $6(20.0)$ & \\
\hline Mean \pm SD & $51.0 \pm 6.9$ & $53.8 \pm 6.2$ & \\
\hline \multicolumn{4}{|l|}{ Sex } \\
\hline Male & $27(90)$ & $28(93.3)$ & $p=0.613$ \\
\hline Female & $3(10)$ & $2(6.7)$ & \\
\hline
\end{tabular}

Figures in the parentheses indicate corresponding \%; $\left(\chi^{2}\right)$ Test was employed to analyse the data.

\begin{tabular}{|c|c|c|c|}
\hline \multicolumn{4}{|c|}{$\begin{array}{l}\text { TABLE II. Comparison of preoperative drugs used between } \\
\text { two groups }\end{array}$} \\
\hline \multirow{2}{*}{$\begin{array}{l}\text { Preoperative } \\
\text { drugs used }\end{array}$} & \multicolumn{2}{|c|}{ Group } & \multirow[b]{2}{*}{ p-value } \\
\hline & $\begin{array}{c}\text { Magnesium } \\
(\mathrm{n}=30)\end{array}$ & $\begin{array}{l}\text { Control } \\
(n=30)\end{array}$ & \\
\hline \multicolumn{4}{|c|}{ Calcium channel } \\
\hline Blocker \# & $15(50.0)$ & $15(50.0)$ & 0.897 \\
\hline Beta-blocker ${ }^{\#}$ & $11(36.7)$ & $5(16.7)$ & 0.080 \\
\hline
\end{tabular}

Figures in the parentheses denote corresponding percentage. \# Chi-square $\left(\chi^{2}\right)$ Test was employed to analyse the data.

\begin{tabular}{|c|c|c|c|}
\hline \multirow{2}{*}{$\begin{array}{l}\text { Preoperative } \\
\text { characteristics }\end{array}$} & \multicolumn{2}{|c|}{ Group } & \multirow[b]{2}{*}{$\mathrm{p}$-value } \\
\hline & $\begin{array}{l}\text { Magnesium } \\
(\mathrm{n}=30)\end{array}$ & $\begin{array}{l}\text { Control } \\
(n=30)\end{array}$ & \\
\hline Diabetes ${ }^{\#}$ & $16(53.3)$ & $19(63.3)$ & 0.432 \\
\hline Previous Ml ${ }^{\#}$ & $6(20.0)$ & $8(26.7)$ & 0.542 \\
\hline Hypertension ${ }^{\#}$ & $21(70.0)$ & $19(63.3)$ & 0.584 \\
\hline Ejection fraction* & $56.2 \pm 8.5$ & $53.5 \pm 5.4$ & 0.143 \\
\hline
\end{tabular}

Figures in the parentheses indicate corresponding percentage. \# Chi-square $\left(\chi^{2}\right)$ Test was employed to analyze the data.

*Data were analysed using Student's t-Test and were presented as mean \pm SD.

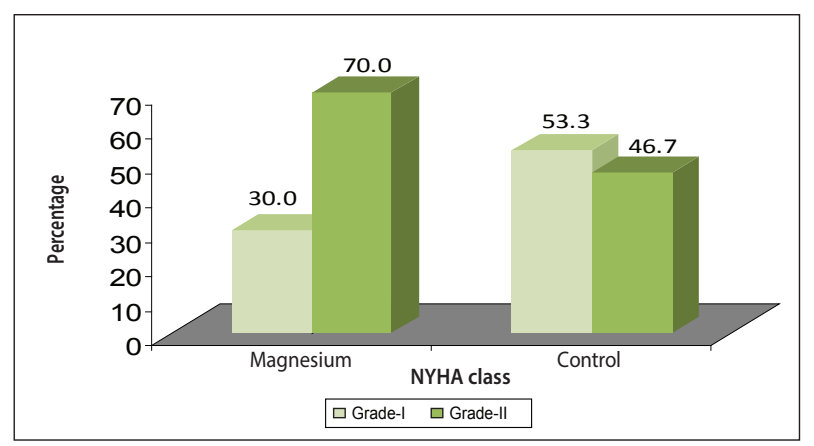

Fig. 1: Comparison of NYHA class between groups

\section{TABLE IV. Number grafts used between two groups}

\begin{tabular}{lccc}
\multirow{2}{*}{$\begin{array}{l}\text { No. of graft } \\
\text { required }\end{array}$} & \multicolumn{2}{c}{ Group } & \\
\cline { 2 - 3 } & $\begin{array}{c}\text { Magnesium } \\
(\mathrm{n}=30)\end{array}$ & $\begin{array}{c}\text { Control } \\
(\mathrm{n}=30)\end{array}$ & p-value \\
2 & $4(13.3)$ & $5(16.7)$ & \\
3 & $20(67.7)$ & $16(53.3)$ & 0.421 \\
4 & $6(20.0)$ & $9(30.0)$ &
\end{tabular}

Figures in the parenthesis denote corresponding \%; $\chi^{2}$ Test was employed to analyse the data.

TABLE V. Comparison of arrhythmia profile between two groups

\begin{tabular}{|c|c|c|c|}
\hline \multirow{2}{*}{$\begin{array}{l}\text { Arrhythmia } \\
\text { profiles }\end{array}$} & \multicolumn{2}{|c|}{ Group } & \multirow[b]{2}{*}{$\mathrm{p}$-value } \\
\hline & $\begin{array}{l}\text { Magnesium } \\
(\mathrm{n}=30)\end{array}$ & $\begin{array}{l}\text { Control } \\
(n=30)\end{array}$ & \\
\hline Arrhythmia (developed) $\#$ & $3(10.0)$ & $5(16.7)$ & $0.353^{\mathrm{NS}}$ \\
\hline \multicolumn{4}{|l|}{ Timing of arrhythmia developed* } \\
\hline \multirow[t]{2}{*}{$1-1.5$ hours } & $2(66.7)$ & $4(80.0)$ & \\
\hline & & & $0.673^{\text {NS }}$ \\
\hline $1.5-2$ hours & $1(33.3)$ & $1(20.0)$ & \\
\hline \multicolumn{4}{|l|}{ Type of arrhythmia* } \\
\hline \multirow[t]{2}{*}{ Supraventricular tachycardia } & ia 00 & $1(20.0)$ & \\
\hline & & & $0.408^{\mathrm{NS}}$ \\
\hline Atrial fibrillation & $3(100.0)$ & $4(80.0)$ & \\
\hline
\end{tabular}

\# Fisher Exact Test was done to analyse the data; NS = Not significant ${ }^{*}$ Chi-square $\left(\chi^{2}\right)$ Test was employed to analyse the data. 


\begin{tabular}{lccc}
\hline \multirow{2}{*}{ TABLE VI. Comparison of systolic BP between two groups } \\
\cline { 2 - 3 } Systolic BP & \multicolumn{2}{c}{ Group } & \\
\cline { 2 - 3 } & $\begin{array}{c}\text { Magnesium } \\
(\mathrm{n}=30)\end{array}$ & $\begin{array}{c}\text { Control } \\
(\mathrm{n}=30)\end{array}$ & p-value \\
At baseline & $138.4 \pm 7.3$ & $137.5 \pm 8.1$ & 0.665 \\
At 30 minutes & $131.1 \pm 7.6$ & $128.4 \pm 7.2$ & 0.170 \\
At 1 hour & $118.5 \pm 9.4$ & $115.9 \pm 7.5$ & 0.250 \\
At 1.5 hour & $111.5 \pm 10.3$ & $107.5 \pm 5.1$ & 0.060 \\
At 2 hours & $109.5 \pm 9.5$ & $105.3 \pm 6.7$ & 0.051 \\
At 2.5 hours & $110.6 \pm 7.1$ & $109.1 \pm 8.9$ & 0.485 \\
At 3 hours & $116.9 \pm 10.2$ & $119.3 \pm 8.0$ & 0.321 \\
At 3.5 hours & $115.5 \pm 23.3$ & $122.0 \pm 7.9$ & 0.157 \\
At 4 hours & $120.3 \pm 10.7$ & $126.5 \pm 5.6$ & 0.007
\end{tabular}

\# Data were analysed using Repeated Measure ANOVA \& were presented as mean \pm SD.

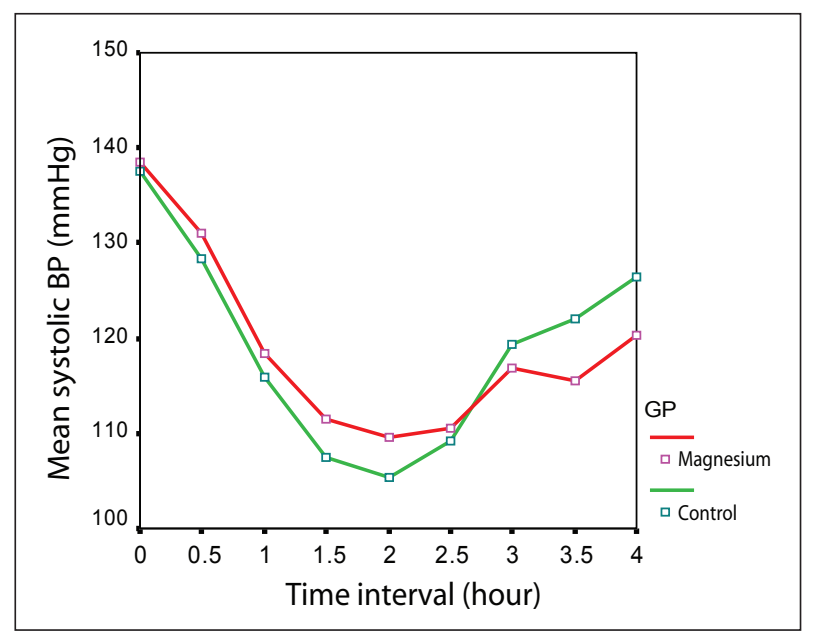

Fig 2. Monitoring of SBP at different time interval

TABLE VII. Comparison of diastolic BP between two groups

\begin{tabular}{lccc} 
& \multicolumn{2}{c}{ Group } & \\
\cline { 2 - 3 } $\begin{array}{l}\text { Diastolic BP } \\
(\mathrm{mmHg})\end{array}$ & $\begin{array}{c}\text { Magnesium } \\
(\mathrm{n}=30)\end{array}$ & $\begin{array}{c}\text { Control } \\
(\mathrm{n}=30)\end{array}$ & p-value \\
At baseline & $85.2 \pm 4.5$ & $82.9 \pm 5.1$ & 0.077 \\
At 30 minutes & $82.1 \pm 3.0$ & $81.9 \pm 4.1$ & 0.859 \\
At 1 hour & $78.5 \pm 5.9$ & $79.3 \pm 4.1$ & 0.545 \\
At 1.5 hour & $78.8 \pm 4.6$ & $78.1 \pm 5.9$ & 0.612 \\
At 2 hours & $78.3 \pm 7.2$ & $77.9 \pm 6.8$ & 0.841 \\
At 2.5 hours & $80.8 \pm 4.7$ & $80.0 \pm 6.1$ & 0.559 \\
At 3 hours & $82.2 \pm 3.6$ & $82.9 \pm 2.9$ & 0.413 \\
At 3.5 hours & $80.5 \pm 6.6$ & $83.7 \pm 3.3$ & 0.020 \\
At 4 hours & $80.5 \pm 5.2$ & $84.5 \pm 3.2$ & 0.001
\end{tabular}

\# Data were analysed using Repeated Measure ANOVA \& were presented as mean \pm SD.

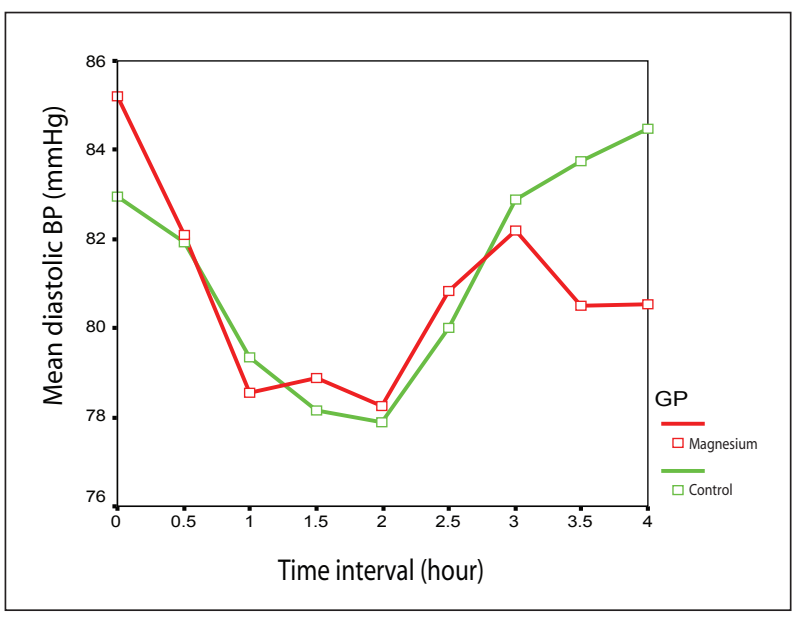

Fig 3. Monitoring of DBP at different time interval

TABLE VIII. Comparison of heart rate between two groups

\begin{tabular}{lccc}
$\begin{array}{l}\text { Heart rate } \\
(\mathrm{bpm})\end{array}$ & \multicolumn{2}{c}{ Group } & p-value \\
\cline { 2 - 3 } & $\begin{array}{c}\text { Magnesium } \\
(\mathrm{n}=30)\end{array}$ & $\begin{array}{c}\text { Control } \\
(\mathrm{n}=30)\end{array}$ & \\
At baseline & $72 \pm 4$ & $74 \pm 5$ & 0.037 \\
At 30 minutes & $79 \pm 14$ & $85 \pm 6$ & 0.031 \\
At 1 hour & $87 \pm 6$ & $90 \pm 5$ & 0.013 \\
At 1.5 hour & $82 \pm 5$ & $85 \pm 6$ & 0.014 \\
At 2 hours & $80 \pm 6$ & $84 \pm 5$ & 0.002 \\
At 2.5 hours & $83 \pm 6$ & $83 \pm 15$ & 0.912 \\
At 3 hours & $88 \pm 5$ & $84 \pm 5$ & 0.005 \\
At 3.5 hours & $80 \pm 5$ & $85 \pm 5$ & 0.001 \\
At 4 hours & $82 \pm 6$ & $86 \pm 6$ & 0.025
\end{tabular}

\# Data were analysed using Repeated Measure ANOVA \& were presented as mean \pm SD.

TABLE IX. Comparison of CVP between two groups

\begin{tabular}{|c|c|c|c|}
\hline \multirow[b]{2}{*}{ CVP\# (cm of water) } & \multicolumn{2}{|c|}{ Group } & \multirow[b]{2}{*}{$\mathrm{p}$-value } \\
\hline & $\begin{array}{l}\text { Magnesium } \\
(\mathrm{n}=30)\end{array}$ & $\begin{array}{l}\text { Control } \\
(n=30)\end{array}$ & \\
\hline At baseline & $10.0 \pm 0.2$ & $11.9 \pm 0.9$ & 0.050 \\
\hline At 30 minutes & $8.4 \pm 0.7$ & $7.7 \pm 0.9$ & 0.001 \\
\hline At 1 hour & $4.9 \pm 0.8$ & $4.8 \pm 0.8$ & 0.636 \\
\hline At 1.5 hour & $7.9 \pm 0.8$ & $7.7 \pm 0.8$ & 0.252 \\
\hline At 2 hours & $8.9 \pm 0.8$ & $8.5 \pm 0.9$ & 0.109 \\
\hline At 2.5 hours & $10.3 \pm 0.7$ & $8.8 \pm 0.8$ & 0.007 \\
\hline At 3 hours & $8.3 \pm 0.6$ & $6.1 \pm 0.7$ & $<0.001$ \\
\hline At 3.5 hours & $11.5 \pm 0.6$ & $9.7 \pm 0.9$ & 0.001 \\
\hline At 4 hours & $12.0 \pm 0.6$ & $10.8 \pm 1.0$ & 0.001 \\
\hline
\end{tabular}

\# Data were analysed using Repeated Measure ANOVA \& were presented as mean \pm SD. 


\section{DISCUSSION:}

Arrhythmia is not uncommon after coronary artery bypass grafting surgery (CABG). Publications as early as 1930 s documented that magnesium deficiency can precipitate ventricular arrhythmias and that treatment with magnesium has antiarrhythmic potency on the supraventricular as well as ventricular level. ${ }^{6}$ Based on this concept, the present study was conducted to see whether peroperative magnesium infusion could reduce the incidence of arrhythmia in patients undergoing CABG surgery. In the present study all the baseline characteristics except NYHA functional class were almost identical between the study and the control groups. The NYHA class II subjects demonstrated their significant presence in the Magnesium group (70\%) compared to that in the Control group (46.7\%). Males were predominant in both the groups. Kaplan 7 also reported a male predominance in either group. Toraman ${ }^{8}$ reported no difference in the use of preoperative calcium channel blocker use $(p=0.420)$. Kaplan ${ }^{9}$ showed that there was no difference between the magnesium and control group in terms of preoperative use of beta-blockers $(p=0.717)$ and calcium-channel blockers $(p=0.661)$. None of the factors like diabetes, previous MI, hypertension and ejection fraction was found to be significantly different between groups. Kaplan ${ }^{7}$ also reported distribution of previous myocardial infarction, hypertension, diabetes mellitus in the magnesium and control group to be almost identical. Toraman ${ }^{8}$ found no significant difference in NYHA functional class between magnesium and control group. There was no difference between the groups in terms of number of grafts required.

All peroperative variables like development of arrhythmia, timing of arrhythmia and types arrhythmia encountered were almost similar in magnesium and control group ( $p>0.05)$. Majority of the patients in both groups experienced atrial fibrillation. Three patients in the magnesium group and four patients in the control group developed atrial fibrillation. Only one patient in the control group exhibited supraventricular tachycardia. Fanning ${ }^{10}$, Karmy-Jones and associates $^{11}$ in a similar study did not find any significant differences between treatment and control groups in terms of incidence of atrial fibrillation development. Kaplan ${ }^{7}$ reported supraventricular tachycardia in magnesium and control group in $2 \%$ and $4 \%$ cases respectively and artrial fibrillation in $15 \%$ and $16 \%$ respectively. The reported incidence of supraventricular arrhythmia ranges from $40-47 \%$, wher eas ventricular arrhythmia was over $30 \% .{ }^{12}$ There are reports suggesting that magnesium reduces the incidence of ventricular arrhythmia \& supraventricular arrhythmias including atrial fibrillation. ${ }^{13,14}$

Harris and associates ${ }^{15}$ found an incidence of arrhythmia of $22 \%$ after $16 \mathrm{mmol}$ of magnesium chloride infusion, compared with $63 \%$ in control patients. The authors measured plasma and urine magnesium. ${ }^{2}$ In another study administration of 2 $\mathrm{gm}$ of magnesium chloride after termination of CPB resulted in a reduction in the incidence of ventricular arrhythmia from 34 to $16 \% .^{1}$ This group first used ultra filterable magnesium as a reflection of ionized and chelated magnesium, thus excluding the protein-bound fraction. Casthely and colleagues ${ }^{16}$ administered four different regimens of magnesium sulfate during CPB and found that the highest magnesium regimen was associated with the least incidence of postoperative cardiac arrhythmia. In these studies, magnesium administration prevented ventricular, but not supraventricular, rhythm abnormalities. Other authors found a greater effect on supraventricular arrhythmia: Wistbacka ${ }^{17}$ demonstrated an incidence of $\mathrm{AF}$ in $24 \%$ of patients who received a high magnesium infusion regimen compared with $45 \%$ in patients receiving a low-magnesium regimen. Fanning ${ }^{10}$ demonstrated a decrease in the frequency of postoperative $A F$ in magnesium- treated patients compared with placebo but found no difference in the incidence of ventricular arrhythmia. Balser ${ }^{18}$ demonstrated that small dose of postoperative magnesium supplementation reduced the incidence of ventricular arrhythmia, but larger doses of magnesium were needed to prevent AF. Thus, the 
findings of the present study and those of other investigators discussed so far suggest that magnesium could reduce the incidence arrhythmia during peroperative period to acceptable level in patients undergoing CABG. The systolic and diastolic blood pressures, heart rate and central venous pressures in patients receiving magnesium also did not go beyond normal range during the whole period of observation.

\section{CONCLUSION:}

The use of magnesium as an antiarrhythmic drug for extrasystole, supraventricular tachycardia and atrial fibrillation has been a matter of increasing interest and controversy over recent years. In view of the influence of magnesium on electrical stability and function of myocardial cells as well as the myocardium as a whole, the drug appears valuable in a wide array of arrhythmias. Arrhythmia developed after CABG surgery is a serious cause of morbidity. The incidence of arrhythmia could be lowered with magnesium supplement in Off-Pump Beating Heart CABG surgery. However, as the present study was carried out on a small sample, it is difficult to generalize the findings to the reference population. Further study with large sample is recommended to draw a generalizable conclusion.

\section{REFERENCES:}

1. Tiryakioglu O, Demirtas S, Ari H. Magnesium sufate and amiodarne prophylaxis for prevention of postoperative arrhythmia in coronary bypass operations. Journal Cardiothoracic Surgery 2009;4(8): 1-6.

2. Kapaln M, Kut MS, Icer UA, Demirtas MM. Intravenous magnesium sulfate prophylaxis for atrial fibrillation after coronary artery bypass surgery. J Thorac Cardiovase Surg 2003;125:344-52.

3. Marcia L, Bill B, Moberg L. Magnesium sulfate for prevention of postoperative atrial fibrillation in patients undergoing coronary artery bypass grafting. $\mathrm{Am} \mathrm{J}$ Health System Pharmacy 2005;62(4):397-9.

4. Akther R, Rashid M. Is low level of serum ionized magnesium for eclampsia? Journal of Bangladesh College of Physicians and Surgeons 2009;27(2):77.

5. Marik PE. Hand Book of Evidence Based Critical Care: Electrolyte Distribution: $1^{\text {st }}$ edition, Chapter-30, p. 258.
6. Zwillinger L. Über die Magnesiumwirkung auf das Herz. Klin Wochenschr 1935;14:1429-33.

7. Kaplan M, Kut MS, Icer UA, Demirtas MM. Intravenous magnesium sulfate prophylaxis for atrial fibrillation after coronary artery bypass surgery. J Thorac Cardiovasc Surg 2003;125:344-52.

8. Toraman F, Karabulut EH, Alhan HC, Dag ` delen S, \& Tarcan SM. Magnesium Infusion Dramatically Decreases the Incidence of Atrial Fibrillation After Coronary Artery Bypass Grafting. Ann Thorac Surg 2001;72: 1256-62.

9. Kerendi F, Morris CD, Puskas JD. Off-pump coronary bypass surgery for high-risk patients: only in expert centers? Curr Opin Cardiol 2008;23(6):573-8.

10. Fanning WJ, Thomas CS Jr, Roach A. Prophylaxis of atrial fibrillation with magnesium sulphate after coronary artery bypass grafting. Ann Thorac Surg $1991 ; 52: 529-33$.

11. Karmy-Jones R, Hamilton A, Dzavik V, Allegreto $M$, Finegan BA, Koshal A. Magnesium sulfate prophylaxis after cardiac operations. Ann Thorac Surg. 1995; 59:502-7.

12. England MR, Gordon G, Salem M, Chernow B. Magnesium administration and dysrhythmias after cardiac surgery. A placebo-controlled, double-blind, randomized trial. JAMA 1992;268:2395-402.

13. Boyd WC, Thomas SJ. Pro: Magnesium should be administered to all coronary artery bypass graft surgery patients undergoing cardiopulmonary bypass. $J$ Cardiothorac Vasc Anesth 2000;14:339-43.

14. Brackbill ML, Moberg L. Magnesium sulfate for prevention of postoperative atrial fibrillation in patients undergoing coronary artery bypass grafting. Am J Health Syst Pharm 2005;62:397-9.

15. Harris MN, Crowther A, Jupp RA,, Aps C. Magnesium and coronary revascularization. $\mathrm{Br}$ J Anaesth 1988;60: 779-83.

16. Casthely PA, Yoganathan T, Komer C, Kelly M. Magnesium and arrhythmias after coronary artery bypass surgery. J Cardiothorac Vasc Anesth 1994;8:188-91.

17. Wistbacka JO, Koistinen J, Karlqvist KE, Lepojarvi MV, Hanhela R, Laurila J et al. Magnesium substitution in elective coronary artery surgery: a double-blind clinical study. J Cardiothorac Vasc Anesth 1995;9:140-6.

18. Balser JR. Pro: all patients should receive pharmacologic prophylaxis for atrial fibrillation after cardiac surgery. J Cardiothorac Vasc Anesth 1999;13:98-100. 